\title{
An efficient one-pot three-component synthesis of tetrahydrobenzo[b]pyran and 3,4-dihydropyrano[c]chromene derivatives using starch solution as catalyst
}

\author{
Nourallah Hazeri*, Malek Taher Maghsoodlou, Fatemeh Mir, Mehrnoosh Kangani, \\ Hamideh Saravani, Ebrahim Molashahi \\ Department of Chemistry, The University of Sistan and Baluchestan, P.O. Box 98135-674, Zahedan, Iran
}

\section{A R T I C L E I N F O}

Article history:

Received 10 October 2013

Accepted 11 December 2013

Published 20 March 2014

Keywords:

Tetrahydrobenzo[b]pyran

Dihydropyrano $[c]$ chromene

Starch solution

\begin{abstract}
A B S T R A C T
Tetrahydrobenzo $[b]$ pyran and 3,4-dihydropyrano[c]chromene derivatives were synthesized via a one-pot three-component condensation of aromatic aldehydes with malononitrile and dimedone or 4-hydroxycoumarin in excellent yields in the presence of starch solution as a highly efficient homogenous catalyst. The use of a nontoxic and biodegradable catalyst, simple work-up procedure, and short reaction time are advantages of this method.
\end{abstract}

(C) 2014, Dalian Institute of Chemical Physics, Chinese Academy of Sciences. Published by Elsevier B.V. All rights reserved.

the aim of obtaining more biologically potent heterocyclic systems using different catalysts including magnesium oxide [4], silica-bonded 1,4-diazabicyclo[2.2.2]octane [5], silica nanoparticles [6], electro-generated base [7], baker's yeast [8], and amino-functionalized ionic liquid [9]. Other synthetic methods have included the use of microwaves [10], ultrasonic radiation [11], and utilizing additives like hexadecyltrimethylammonium bromide [12], triethylbenzylammonium chloride [13], other alkylammonium salts [14], 4-dodecylbenzenesulfonic acid [15], and (S)-proline [16]. However, limitations of the above methods include poor yields, difficult work-up, and toxic elements. Bandgar and coworkers [17] reported the synthesis of tetrahydrobenzo[b]pyrans in good yield without the use of a catalyst, although prolonged reaction time was required.

Biscoumarins and dihydropyrano $[c]$ chromenes are of considerable interest because they possess a wide range of biological properties [18-24]. A number of methods have been re-

\footnotetext{
* Corresponding author. Tel/Fax: +98-541-2416565; E-mail: nhazeri@chem.usb.ac.ir This work was supported by the the Research Council of the University of Sistan and Baluchestan. DOI: 10.1016/S1872-2067(14)60003-6 | http://www.sciencedirect.com/science/journal/18722067 | Chin. J. Catal., Vol. 35, No. 3, March 2014
} 
ported for the synthesis of biscoumarins [25-28]. However, fewer methods have been described for the synthesis of 3,4-dihydropyrano[c]chromenes [29-31]. Some of these procedures require refluxing for hours in organic solvents, use of expensive catalysts, and tedious work-up procedures. In continuing our research based on multicomponent reactions [32-34], herein we report an efficient one-pot three-component synthesis of tetrahydrobenzo[ $b]$ pyrans and 3,4-dihydropyrano $[c]$ chromene derivatives using starch solution as a biodegradable catalyst under thermal conditions (Scheme 1).

\section{Experimental}

Melting points were measured on an Electrothermal 9100 apparatus. Infrared (IR) spectra were recorded on a JASCO FT-IR-460 plus spectrometer. ${ }^{1} \mathrm{H}$ nuclear magnetic resonance (NMR) spectra were obtained with a Bruker DRX-400 Advance spectrometer with using deuterated dimethylsulfoxide (DMSO) and acetone as solvents. All reagents and solvents were obtained from Fluka or Merck and were used without further purification. Thin-layer chromatography (TLC) was performed on silica-gel Polygram SILG/UV 254 plates.

\subsection{General procedure for preparation of starch solution}

Starch ( $2 \mathrm{~g}$ ) was added to water $(25 \mathrm{ml})$ with magnetic stirring at $25^{\circ} \mathrm{C}$. After $30 \mathrm{~min}$, the solution was filtered to remove insoluble starch (amylose) [35]. The filtered solution was used for synthesis of tetrahydrobenzo[ $b]$ pyran and 3,4-dihydropyrano $[c]$ chromene derivatives.

\subsection{General procedure for synthesis of tetrahydrobenzo[b]pyran derivatives}

A mixture of an aromatic aldehyde (1.0 mmol), malononitrile $(1.0 \mathrm{mmol})$, dimedone $(1.0 \mathrm{mmol})$, and starch solution $(4 \mathrm{ml})$, was stirred at $50{ }^{\circ} \mathrm{C}$. The progress of the reaction was monitored by TLC. After completion of the reaction, the reaction mixture was cooled to room temperature (RT), and diluted with water. The mixture was filtered for separation of the product. The crude product was recrystallized from ethanol to afford the pure tetrahydrobenzo[b]pyran derivatives. The desired pure products were characterized by comparison of their

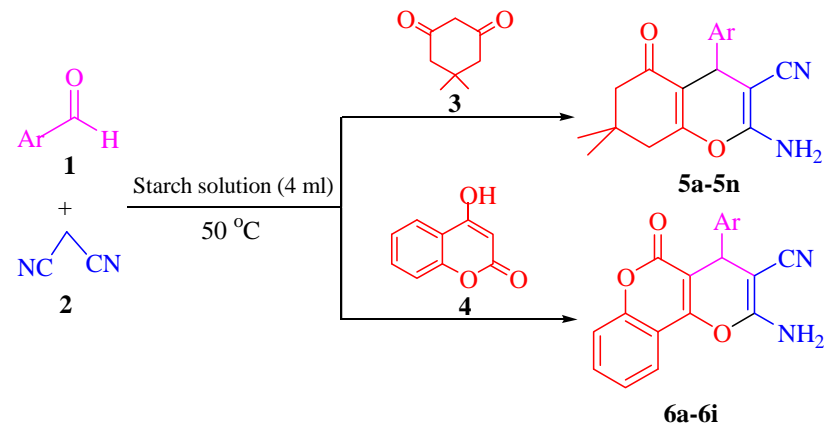

Scheme 1. Synthesis of tetrahydrobenzo[b]pyran and 3,4-dihydropyrano $[c]$ chromene derivatives in the presence of starch solution under thermal conditions. physical data (melting points, IR, and ${ }^{1} \mathrm{H}$ NMR) with those of known compounds in the literature $[13,14]$.

\subsection{General procedure for synthesis of 3,4-dihidropyrano[c] chromene derivatives}

A mixture of an aromatic aldehyde (1.0 mmol), malononitrile $(1.0 \mathrm{mmol}), 4$-hydroxycoumarin $(1.0 \mathrm{mmol})$, and starch solution ( $4 \mathrm{ml}$ ), was stirred at $50{ }^{\circ} \mathrm{C}$. The progress of the reaction was monitored by TLC. After completion of the reaction, the reaction mixture was cooled to room temperature, and diluted with water. The mixture was filtered for separation of the product. The crude product was recrystallized from ethanol to afford the pure 3,4-dihidropyrano[c]chromene derivatives. The desired pure products were characterized by comparison of their physical data (melting points, IR, and ${ }^{1} \mathrm{H}$ NMR) with those of known compounds in the literature [26,28].

\subsection{Spectral data for selected products}

2-Amino-7,7-dimethyl-5-oxo-4-phenyl-5,6,7,8-tetrahydro-4 H-chromene-3-carbonitrile (5a). IR ( $\mathrm{KBr}, \mathrm{cm}^{-1}$ ): 3323, 3395, 3211, 2199, 1680; ${ }^{1} \mathrm{H}$ NMR (400 MHz, DMSO- $\left.d_{6}\right): \delta 1.04(3 \mathrm{H}, \mathrm{s})$, $1.13(3 \mathrm{H}, \mathrm{s}), 2.16(1 \mathrm{H}, \mathrm{d}, J=16.2 \mathrm{~Hz}), 2.28(1 \mathrm{H}, \mathrm{d}, J=16.2 \mathrm{~Hz})$, $2.58(2 \mathrm{H}, \mathrm{s}), 4.30(1 \mathrm{H}, \mathrm{s}), 6.25$ (2H, br s), 7.17-7.32 (5H, Ar).

2-Amino-4,5-dihydro-4-(phenyl)-5-oxopyrano[3,2-c]chrom ene-3-carbonitrile (6a). IR (KBr, $\left.\mathrm{cm}^{-1}\right)$ : 3284, 3377, 3179, 2198, 1708; ${ }^{1} \mathrm{H}$ NMR (400 MHz, DMSO- $d_{6}$ ): $\delta 4.58(1 \mathrm{H}, \mathrm{s}), 6.70$ (2H, br s), 7.26-8.01 (9H, Ar).

\section{Results and discussion}

To prepare tetrahydrobenzo[b]pyran and 3,4-dihydropyrano[c]chromene derivatives in a more efficient way, and to minimize the reaction time and the amount of catalyst required, the reaction of benzaldehyde $(1.0 \mathrm{mmol})$, malononitrile (1.0 mmol), and dimedone (1.0 mmol) or 4-hydroxycoumarin $(1.0 \mathrm{mmol})$ was selected as a model system. The use of different amounts of catalyst $(1,2,3,4$, and $5 \mathrm{ml})$ at different temperature was investigated. The best result was obtained with $4 \mathrm{ml}$ of starch solution at $50{ }^{\circ} \mathrm{C}$ (Tables 1 and 2).

Using these optimized reaction conditions, the scope and ef-

\section{Table 1}

Optimization of temperature in synthesis of tetrahydrobenzo[b]pyran derivatives under thermal conditions.

\begin{tabular}{lcc} 
& Tsolated yield (\%) \\
\hline Entry & $\mathrm{RT}$ & - \\
1 & 10 & 59 \\
2 & 20 & 58 \\
3 & 30 & 69 \\
4 & 40 & 85 \\
5 & 50 & 92 \\
6 & 60 & 92 \\
7 & 70 & 92 \\
8 &
\end{tabular}


Table 2

Optimization of temperature in synthesis of 3,4-dihydropyrano[c] chromene derivatives under thermal conditions.

\begin{tabular}{lcc} 
& \\
Entry & Temperature $\left({ }^{\circ} \mathrm{C}\right)$ & Isolated yield (\%) \\
\hline 1 & $\mathrm{RT}$ & 55 \\
2 & 10 & 57 \\
3 & 20 & 70 \\
4 & 30 & 83 \\
5 & 40 & 92 \\
6 & 50 & 92 \\
7 & 60 & 92 \\
8 & 70 &
\end{tabular}

ficiency of the reaction were explored for the synthesis of a wide variety of substituted tetrahydrobenzo[b]pyrans and 3,4dihydropyrano[c]chromene derivatives using aromatic aldehydes, malononitrile, and 1,3-dicarbonyl compounds. The results are summarized in Table 3. The desired pure products were characterized by comparison of their physical data (melting points, IR, and ${ }^{1} \mathrm{H}$ NMR) with those of known compounds in the literature.

Interestingly, a variety of aryl aldehydes including electronwithdrawing or electron-releasing substituents (ortho-, meta-, and para-substituted) participated well in this reaction and gave the tetrahydrobenzo[b]pyran and 3,4-dihydropyrano $[c]$ chromene derivatives in good to excellent yield. The yields obtained when using aliphatic aldehydes were at trace levels.

Based on literature reports $[21,28]$, we proposed a mechanism for the synthesis of tetrahydrobenzo[b]pyran and 3,4-


Scheme 2. Proposed mechanism for the synthesis of tetrahydroben$\mathrm{zo}[b]$ pyran derivatives in the presence of starch solution as catalyst under thermal conditions.

dihydropyrano[ $[c]$ chromene derivatives in the presence of starch solution as catalyst (Scheme 2). First, Knoevenagal condensation between $\mathbf{1}$ and $\mathbf{2}$ produced 2-benzylidenemalononitrile 3 . Michael addition of $\mathbf{3}$ with $\mathbf{5}$ (1,3-dicarbonyl com-

Table 3

Preparation of tetrahydrobenzo $[b]$ pyran and 3,4-dihydropyrano $[c]$ chromene derivatives in the presence starch solution as biodegradable catalyst under thermal conditions.

\begin{tabular}{|c|c|c|c|c|c|c|c|}
\hline \multirow{2}{*}{ Entry } & \multirow{2}{*}{$\mathrm{Ar}$} & \multirow{2}{*}{ 1,3-Dicabonyl } & \multirow{2}{*}{ Product } & \multirow{2}{*}{$\begin{array}{l}\text { Time } \\
\text { (min) }\end{array}$} & \multirow{2}{*}{$\begin{array}{c}\text { Isolated } \\
\text { yield (\%) }\end{array}$} & \multicolumn{2}{|c|}{ Melting point $\left({ }^{\circ} \mathrm{C}\right)$} \\
\hline & & & & & & Observed & Reported \\
\hline 1 & $\mathrm{C}_{6} \mathrm{H}_{5}$ & 3 & $5 a$ & 30 & 92 & $230-232$ & $228-230$ [15] \\
\hline 2 & $2-\mathrm{Cl} \mathrm{C}_{6} \mathrm{H}_{4}$ & 3 & $5 b$ & 65 & 82 & $210-212$ & $208-210$ [13] \\
\hline 3 & $4-\mathrm{Cl} \mathrm{C}_{6} \mathrm{H}_{4}$ & 3 & $5 c$ & 45 & 85 & $208-210$ & $210-212$ [13] \\
\hline 4 & $2,4-(\mathrm{Cl})_{2} \mathrm{C}_{6} \mathrm{H}_{3}$ & 3 & $5 d$ & 35 & 94 & $120-122$ & $115-117$ [18] \\
\hline 5 & $2-\mathrm{NO}_{2} \mathrm{C}_{6} \mathrm{H}_{4}$ & 3 & $5 e$ & 40 & 90 & $227-230$ & $224-226[16]$ \\
\hline 6 & $3-\mathrm{NO}_{2} \mathrm{C}_{6} \mathrm{H}_{4}$ & 3 & $5 f$ & 35 & 94 & $210-212$ & $208-210$ [20] \\
\hline 7 & $4-\mathrm{NO}_{2} \mathrm{C}_{6} \mathrm{H}_{4}$ & 3 & $5 g$ & 45 & 85 & $182-184$ & $183-185$ [11] \\
\hline 8 & 4-Me $\mathrm{C}_{6} \mathrm{H}_{4}$ & 3 & $5 h$ & 65 & 82 & $210-212$ & $212-215$ [20] \\
\hline 9 & 4-OH-3-OMe $\mathrm{C}_{6} \mathrm{H}_{3}$ & 3 & $5 \mathbf{i}$ & 40 & 84 & $228-230$ & $226-230[12]$ \\
\hline 10 & $4-(\mathrm{Me})_{2} \mathrm{~N} \mathrm{C}_{6} \mathrm{H}_{4}$ & 3 & $5 \mathbf{j}$ & 70 & 86 & $220-222$ & 218-220 [19] \\
\hline 11 & $2,3-\mathrm{OMe} \mathrm{C}_{6} \mathrm{H}_{3}$ & 3 & $5 \mathbf{k}$ & 35 & 85 & $216-218$ & $217-219$ [13] \\
\hline 12 & $4-\mathrm{OH} \mathrm{C} \mathrm{H}_{4}$ & 3 & 51 & 75 & 83 & $206-208$ & 204-206 [17] \\
\hline 13 & thiophene-2-carbaldehyde & 3 & $5 \mathrm{~m}$ & 40 & 90 & $212-214$ & $210-212$ [17] \\
\hline 14 & 2-Furaldehyde & 3 & $5 n$ & 35 & 95 & $220-222$ & $222-224[21]$ \\
\hline 15 & $\mathrm{C}_{6} \mathrm{H}_{5}$ & 4 & $6 \mathbf{a}$ & 25 & 95 & $258-260$ & $258-259[26]$ \\
\hline 16 & $3-\mathrm{NO}_{2} \mathrm{C}_{6} \mathrm{H}_{4}$ & 4 & $6 b$ & 60 & 86 & $260-262$ & $262-264[26]$ \\
\hline 17 & $4-\mathrm{NO}_{2} \mathrm{C}_{6} \mathrm{H}_{4}$ & 4 & $6 c$ & 45 & 95 & $255-257$ & $258-260$ [27] \\
\hline 18 & 4-Me $\mathrm{C}_{6} \mathrm{H}_{4}$ & 4 & $6 e$ & 55 & 85 & $253-255$ & $254-256[28]$ \\
\hline 19 & $2-\mathrm{Cl} \mathrm{C}_{6} \mathrm{H}_{4}$ & 4 & $6 f$ & 50 & 82 & $275-277$ & $273-274[29]$ \\
\hline 20 & $4-\mathrm{Cl} \mathrm{C}_{6} \mathrm{H}_{4}$ & 4 & $6 \mathrm{~g}$ & 35 & 90 & $263-265$ & $263-265$ [26] \\
\hline 21 & $2,4-(\mathrm{Cl})_{2} \mathrm{C}_{6} \mathrm{H}_{3}$ & 4 & $6 h$ & 40 & 87 & $258-260$ & $261-262$ [27] \\
\hline 22 & $4-\mathrm{OH} \mathrm{C} \mathrm{H}_{4}$ & 4 & $6 i$ & 25 & 92 & $260-263$ & $265-266$ [26] \\
\hline
\end{tabular}


pound), followed by cyclization and tautomerization then afforded the corresponding product.

\section{Conclusions}

We report a novel one-pot three-component synthesis of functionalized tetrahydrobenzo[b]pyran and 3,4-dihydropyrano[c]chromene derivatives in the presence of starch solution as catalyst. This reaction series was found to be highly effective under thermal conditions. Starch is an effective catalyst and provides a new and useful method for the synthesis of pyran annulated heterocyclic systems by condensation of arylaldehydes, 1,3-dicarbonyl compounds, and malononitrile. The catalyst is environmentally friendly, inexpensive, clean, safe, nontoxic, and easily obtained. Moreover, the procedure offers several advantages including high yields, clean reaction conditions, and no pollution threat to the environment, which together make a useful and attractive process for synthesis of these compounds.

\section{Acknowledgments}

We are thankful of the University of Sistan and Baluchestan Research Council for the partial support of this research.

\section{References}

[1] Niknam K, Borazjani N, Rashidian R, Jamali A. Chin J Catal (催化学 报), 2013, 34: 2245

[2] Kumar A, Gupta M K, Kumar M. Green Chem, 2012, 14: 290

[3] Singh K, Singh J, Singh H. Tetrahedron, 1996, 52: 14273
[4] Ye Z J, Xu R B, Shao X S, Xu X Y, Li Z. Tetrahedron Lett, 2010, 51: 4991

[5] Hasaninejad A, Shekouhy M, Golzar N, Zare A, Doroodmand M M. Appl Catal A, 2011, 402: 11

[6] Safaei-Ghomi J, Teymuri R, Shahbazi-Alavi H, Ziarati A. Chin Chem Lett, 2013, 24: 921

[7] Fotouhi L, Heravi M M, Fatehi A, Bakhtiari K. Tetrahedron Lett, 2011, 48: 5379

[8] Pratap U R, Jawale D V, Netankar P D, Mane R A. Tetrahedron Lett, 2011, 52: 5817

[9] Sallami M, Caignaert V, Hamdad M, Belarbi A, Sari-Mohamed I, Bahmani A, Bettahar N. C R Chim, 2011, 14: 887

[10] Devi I, Bhuyan P J. Tetrahedron Lett, 2004, 45: 8625

[11] Tu S J, Jiang H, Zhuang Q Y, Miao C B, Shi D Q, Wang X S, Gao Y. Chin J Org Chem, 2003, 23: 488

[12] Jin T S, Wang A Q, Wang X, Zhang J S, Li T S. Synlett, 2004: 871

[13] Shi D Q, Zhang S, Zhuang Q Y, Tu S J, Hu H W. Chin J Org Chem, 2003, 23: 877

[14] Shi D Q, Mou J, Zhuang Q Y, Wang X S. J Chem Res, 2004: 821

[15] Jin T S, Wang A Q, Zhang J S, Zhang F S, Li T S. Chin J Org Chem, 2004, 24: 1598

[16] Balalaie S, Bararjanian M, Amani A M, Movassagh B. Synlett, 2006: 263

[17] Bandgar S B, Bandgar B P, Korbad B L, Totre J V, Patil S. Aust J Chem, 2007, 60: 305

[18] Green G R, Evans J M, Vong A K. In: Katritzky A R, Rees C W, Scriven E F V O eds. Comprehensive Heterocyclic Chemistry II. Vol. 5. Oxford: Pergamon Press, 1995. 469

[19] Foye W O. Pharmaceutical and Chemical Principles. Italy: Piccin, 1991.416

[20] Bonsignore L, Loy G, Secci D, Calignano A. Eur J Med Chem,1993, 28: 517

[21] Konkoy C S, Fick D B, Cai S X, Lan N C, Keana J F W. WO Patent

\section{Graphical Abstract}

Chin. J. Catal., 2014, 35: 391-395 doi: 10.1016/S1872-2067(14)60003-6

\section{An efficient one-pot three-component synthesis of tetrahydrobenzo[b]pyran and 3,4-dihydropyrano[c]chromene derivatives using starch solution as catalyst}

Nourallah Hazeri *, Malek Taher Maghsoodlou, Fatemeh Mir, Mehrnoosh Kangani, Hamideh Saravani, Ebrahim Molashahi The University of Sistan and Baluchestan, Iran

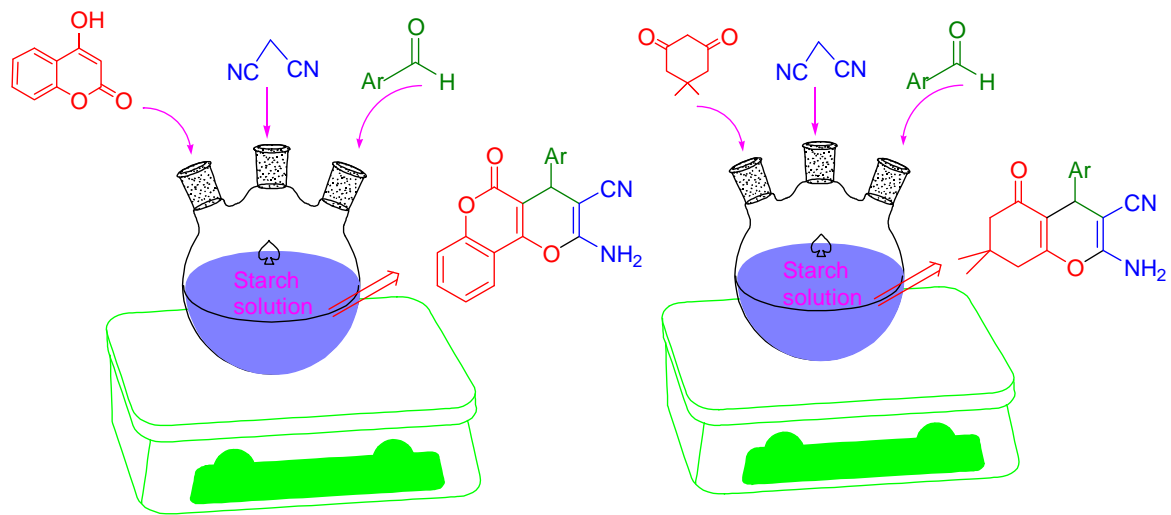

Tetrahydrobenzo[ $b]$ pyran and 3,4-dihydropyrano $[c]$ chromene derivatives were synthesized via one-pot three-component condensation of aromatic aldehydes with malononitrile and dimedone or 4-hydroxycoumarin in excellent yields in the presence starch solution as a highly efficient homogenous catalyst. The use of a nontoxic and biodegradable catalyst, simple work-up procedure, and short reaction time are advantages of this method. 
2000075123A1. 2000

[22] Kostava I, Manolov I, Nicolova I, Konstantinov S, Karaivanova M. EurJ Med Chem, 2001, 36: 339

[23] Chohan Z H, Shaikh A U, Rauf A, Supuran C T. J Enzym Inhib Med Chem, 2006, 21: 741

[24] Zhao H, Neamati N, Hong H X, Mazumder A, Wang S M, Sunder S, Milne G W A, Pommier Y, Burke T R Jr. J Med Chem, 1997, 40: 242

[25] Manolov I, Maichle-Moessmer C, Danchev N. Eur J Med Chem, 2006, 41: 882

[26] Qadir S, Dar A A, Khan K Z. Synth Commun, 2008, 38: 3490

[27] Kidwai M, Bansal V, Mothsra P, Saxena S, Somvanshi R K, Dey S, Singh T P. J Mol Catal A, 2007, 268: 76
[28] Khurana J M, Kumar S. Tetrahedron Lett, 2009, 50: 4125

[29] Shaker R M. Pharmazie, 1996, 51: 148

[30] Chilin A, Marzaro G, Zanatta S, Guiotto A. Tetrahedron Lett, 2007, 48: 3299

[31] Heravi M M, Jani B A, Derikvand F, Bamoharram F F, Oskooie H A. Catal Commun, 2008, 10: 272

[32] Maghsoodlou M T, Habibi-Khorassani S M, Moradi A, Hazeri N, Davodi A, Sajadikhah S S. Tetrahedron, 2011, 67: 8492

[33] Maghsoodlou M T, Marandi G, Hazeri N, Aminkhani A, Kabiri R. Tetrahedron Lett, 2007, 48: 3197

[34] Mousavi M R, Hazeri N, Maghsoodlou M T, Salahi S, HabibiKhorassani S M. Chin Chem Lett, 2013, 24: 411

[35] Green M M, Blankenhorn G, Hart H.J Chem Educ, 1975, 52: 729 